Contents available at: Sri Lanka Journals Online

\title{
Extraction of Microfibrilated Cellulose Using Waste Garment Cotton Fabrics
}

\author{
J.M.R Jayasinghe, A.M.P.B. Samarasekara* and D.A.S. Amarasinghe \\ Department of Materials Science and Engineering, Faculty of Engineering, University of Moratuwa, Moratuwa, Sri Lanka
}

\section{ARTICLE INFO}

\section{Article history:}

Received: 21 August 2019

Accepted: 01 November 2019

Available online: 1 April 2020

\section{Keywords:}

Acid-hydrolysis

Bio-composite

Micro/Nano reinforcing fillers

Micro-Cystalline cellulose

Microfibrillated Cellulose

\section{Citation:}

Jayasinghe, J.M.R, Samarasekara, A. M. P.

B. and Amarasinghe, D.A.S. (2020).

Extraction of Microfibrilated Cellulose

Using Waste Garment Cotton Fabrics.

Tropical Agricultural Research, 31(2): 2128.

DOI: http://doi.org/10.4038/tar.v31i2.8364

Jayasinghe, J.M.R.

https://orcid.org/0000-0003-0225-0903

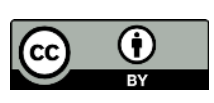

\section{ABSTRACT}

In recent years, there has been an increasing demand for micro/nano cellulose that is unique and extracted from native cellulose has gained much attention. Because of its remarkable physical properties, specific surface chemistry, biological properties such as biodegradability and low toxicity, renewability and low $\mathrm{CO}_{2}$ emissions into atmosphere during its life cycle, cellulose has gained much attention as a polymer reinforcement material. This study was conducted on extraction of Microfibrillated Cellulose (MFC) from waste garment cotton fabric as a source of native cellulose. The study examined the surface morphology and structural properties of MFCs extracted by combination of chemical purification and acid hydrolysis process of cotton fibers. Morphological features (Scanning electron microscopy (SEM)) and structural features (Fourier transformed infrared (FTIR) spectroscopy); X-ray diffraction (XRD) of MFCs were tested. Morphological characterization clearly showed the formation of three dimensional MFCs with sizes in the range of 5-15 $\mu \mathrm{m}$ (length) and 400-600 $\mathrm{nm}$ (diameter). Structural features (FTIR) showed purity in MFCs and most of the impurity components have been removed. X-ray diffraction analysis revealed that MFCs have a higher degree of crystallinity around $56 \%$. These extracted MFCs have a high potential to be used as micro-reinforcement fillers in bio-composites in industrial applications as value-added products.

*Corresponding author : banduamp@gmail.com 


\section{INTRODUCTION}

Nano-cellulose is considered as a novel advanced natural polymer material. Nano cellulose is described as an extracted product of cellulose that is present in plants and bacteria. The family of micro/nano cellulose can be divided into Nanocrystalline cellulose (NCC), nano whiskers, Cellulose nano fibrils (NFC), Microfibrilated cellulose (MFC) and Bacterial Cellulose (BC), which is also referred to as microbial cellulose. The source of the CNC and NFC are usually wood, cotton, hemp, jute, sugar cane, wheat straw, algae, tunicin etc. (Kalia et al., 2009; Dufresne, 2013).

These nano scaled elements can be introduced into the polymer matrices and outstanding physical and mechanical properties can be observed. Of these properties, its ability of reinforcement is especially remarkable. The Young's modulus of native cellulose along the axis gives a value of $167.5 \mathrm{GPa}$. The experimental analysis of elastic modulus of nano whiskers is $143 \mathrm{GPa}$ (Khalil et al., 2014, Kahawita and Samarasekara, 2016). Larger surface area of about $150 \mathrm{~m}^{2} / \mathrm{g}$ and high aspect ratio of 70 are also significant in nano cellulose (Lee et al.,2014, Cao et al.,2016).

Nano cellulose material has been used in a wide variety of applications such as reinforcing filler material in plastic composite, bio degradable agent in bio-composite, bio sensor material, drug delivery agent, scaffolds, filter papers, and paint and coatings. NFC and NCC nano structures are produced by converting large size units ( $\mathrm{mm}$ ) to small units $(\mathrm{nm})$ destructively. Acid hydrolysis is the most commonly used extraction method through removal of amorphous region of native cellulose. Other than the chemical extraction process, mechanical destructive processes can be applied such as high-pressure homogenization and grinding. The amount of crystallinity and the amorphous region found in the native cellulose may vary with the sources of material or plant species. Therefore, the properties of the nano cellulose are largely dependent on the type of the raw material. Cotton that consist of $90 \%$ of cellulose is considered as the best source for extracting nano cellulose throughout the history (Hubbe et al.,2008, Santmarti and Lee, 2018).

Compared with the other sources, cotton fabric has significant advantages such as less pre- treatment requirements, high availability even as a waste in garment industry and high cellulose content and less amount of impurities. This research is based on preparation of MFC by using blend of waste garment cotton fabrics as the source of native cellulose. Obtained MFCs through combination of chemical and mechanical treatments are assessed by spectroscopic techniques, X-ray diffraction (XRD), Fourier transformed infrared (FTIR) scanning electron microscopy (SEM) and thermogravimetric analysis (TGA).

\section{MATERIALS AND METHODS}

\section{Raw material preparation}

Waste garment cotton fabric pieces were used as starting native cellulose material. Fabric samples were selected by comparing FTIR pattern with cotton linters that are shown in Figure 1. Fabric was soaked in water for one hour, cleaned and air dried for 8 hours. FTIR analysis was conducted in fabric selection to identify the presence of cellulose. Cellulose extraction was done after two purification steps, alkali and bleaching treatments. Alkali treatment was carried out to ensure the removal of hemicellulose and other polymeric components, and bleached to remove dye and stain in the fabric. Then, $10 \mathrm{~g}$ of each sample were cut in to small pieces and bleached by using $35 \% \mathrm{H}_{2} \mathrm{O}_{2}$. Fifty grams of raw material was mixed with $250 \mathrm{ml}$ of $\mathrm{H}_{2} \mathrm{O}_{2}$ by $1: 10$ weight ratio in bleaching. Then the solution was heated to $70{ }^{\circ} \mathrm{C}$ for 2 hours, and washed by successive filtration. Alkali treatment was conducted with sodium hydroxide $(10 \% \mathrm{w} / \mathrm{w})$ at $70{ }^{\circ} \mathrm{C}$ for 2 hours, filtered and washed with distilled water until $10 \mathrm{pH}$ was achieved. Chemically purified and bleached cotton fibers were then dried and subjected to extract Micro Crystalline Cellulose (MCC).

\section{Extraction of micro- crystalline cellulose}

The previously reported acid hydrolysis method (Bondeson et al., 2006) was applied 
with minor adaptations. Bleach cotton fibers were mixed with a 1:20 weight ratio of 35 $\mathrm{H}_{2} \mathrm{SO}_{4} \%(\mathrm{w} / \mathrm{w}$ ) while mechanically stirring with a Teflon bar dispersant element. Solution was then treated at $40{ }^{\circ} \mathrm{C}$ for one hour. Reaction was stopped by adding excess amount of distilled water and filtered. The residual was washed and filtered again until it became neutral. Then, obtained MCC powder was measured and stored under a cool $\left(18^{\circ} \mathrm{C}\right)$, dry place for future use.

\section{Extraction of MFC}

Above extracted MCC powder was then subjected to further acid hydrolysis process that was reported earlier (Bondeson et al., 2006, Troedec et al., 2008). Since the acid concentration showed the greatest effect on the product, four samples were prepared at different acid concentration levels. These samples were designated as shown in Table 1. For all the four samples, other parameters were maintained as constants.

Table 1: Sample parameter level $-\mathrm{H}_{2} \mathrm{SO}_{4}$ concentration

\begin{tabular}{cc}
\hline Sample no & $\begin{array}{c}\text { Acid Concentration \% } \\
\text { (w/w) }\end{array}$ \\
\hline 1 & 40 \\
2 & 45 \\
3 & 50 \\
4 & 55 \\
\hline
\end{tabular}

The first step was to prepare MCC suspension with dissolving MCC powder in desired amount of distilled water and put in an ice bath while constantly stirring. Acid Hydrolysis was carried out under different acid concentrations as per the Table 1 . Then the sulfuric acid was added drop wise until it reached the required concentration at each level of sample. Then the suspension was heated within $5 \mathrm{~min}$ to reach the temperature mentioned in Table 02. Then the suspension was washed with the distilled water by repeating centrifuging cycles. Final washing was followed by conducting dialysis process until washed water reached constant $\mathrm{pH}$.
Then, the samples were sonicated at 20-25 $\mathrm{kHz}$ and an output power of $800 \mathrm{~W}$ in an ice bath to avoid excess heat generation. All the four samples were then freeze dried and subjected to analysis.

Table 2: Sample parameter level

\begin{tabular}{lll}
\hline Parameter & Unit & Level \\
\hline MCC concentration & $\mathrm{g} / 100 \mathrm{ml}$ & 5 \\
Hydrolysis time & $\mathrm{min}$ & 180 \\
Temperature & $\mathrm{Co}$ & 45 \\
Centrifuging speed & $\mathrm{rpm}$ & 10000 \\
Centrifuging time & $\mathrm{min}$ & 8 \\
Sonication time & $\mathrm{min}$ & 10 \\
Dialysis time & $\mathrm{hr}$ & 72 \\
\hline
\end{tabular}

\section{RESULTS AND DISCUSSION}

\section{Yield of the product}

The nano cellulose yield was highly dependent on the concentration of the reaction mixture. When the reaction mixture sulfuric acid concentration was increased the amorphous part of the cellulose reduced.

Table 3: Yield under four concentration levels of acid concentration

\begin{tabular}{cc}
\hline Sample no & Yield (mass) \\
\hline 1 & $32.23 \%$ \\
2 & $29.12 \%$ \\
3 & $25.86 \%$ \\
4 & $18.47 \%$ \\
\hline
\end{tabular}

\section{Analysis of raw materials}

ATR - FTIR Spectrums of five samples of cotton fabrics, resultant bleached cotton and fresh raw cotton linters were obtained in the wave number range between 3600 and $800 \mathrm{~cm}^{-1}$, at a spectral resolution of $4 \mathrm{~cm}^{-1}$. These materials were analyzed to confirm the presence of cellulose as the source materials. 


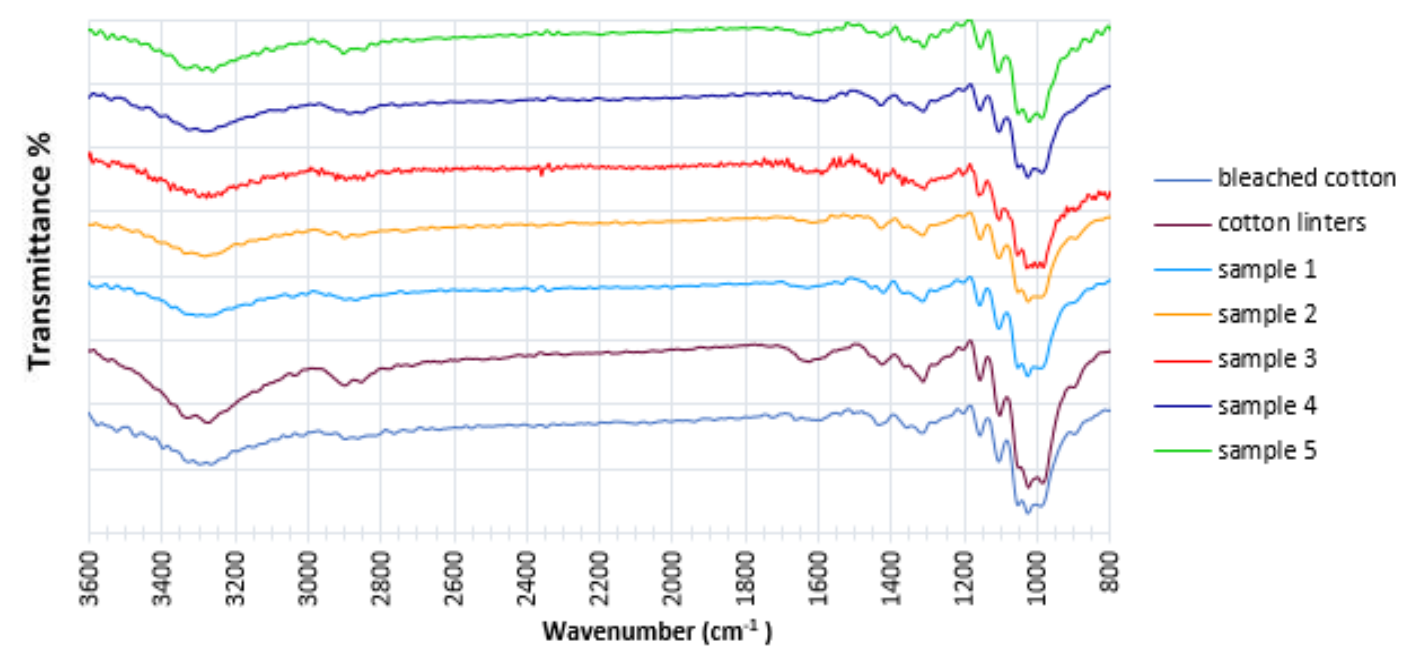

\section{Figure 1: FTIR spectrums of five type of cotton fabric, raw cotton linters and bleached cotton fabric blend}

In Figure 1, the spectral bands were observed in two wave number regions $366-2800 \mathrm{~cm}^{-1}$ and $1650-800 \mathrm{~cm}^{-1}$. The observed peak in the wave number range $3600-2900 \mathrm{~cm}^{-1}$ is the characteristic stretching vibration of polysaccharide of $\mathrm{O}-\mathrm{H}$ and $\mathrm{C}-\mathrm{H}$ bonds. The broad peak at $3175-3490 \mathrm{~cm}^{-1}$ is $\mathrm{O}-\mathrm{H}$ stretching hydrogen bonds for cellulose and absorbed moisture. This peak includes inter and intra- molecular hydrogen bond vibration in cellulose. The band at $2894 \mathrm{~cm}^{-1}$ is for $\mathrm{C}-\mathrm{H}$ stretching vibration in hydrocarbon of polysaccharides. The characteristic bands that assigned to cellulose were observed at 1630$800 \mathrm{~cm}^{-1}$. The peak observed at $1633 \mathrm{~cm}^{-1}$ was attributed to the vibration of absorbed water molecules of cellulose. The spectral peaks that were observed at 1428, 1367,1334 and 1027 $\mathrm{cm}^{-1}$ corresponded to stretching and bending vibrations of $-\mathrm{CH}_{2}$ and $\mathrm{C}-\mathrm{H}, \mathrm{O}-\mathrm{H}$ and $\mathrm{C}-\mathrm{O}$ bonds in Cellulose. The spectral peaks at 1160 $\mathrm{cm}^{-1}$ and $1110 \mathrm{~cm}^{-1}$ ring $\mathrm{C}-\mathrm{C}$ bending vibration and $\mathrm{C}-\mathrm{O}-\mathrm{C}$ in cellulose. The spectral peak at $896 \mathrm{~cm}^{-1}$ is due to $\mathrm{C}-\mathrm{H}$ vibration in cellulose that is mentioned as characteristic absorption of cellulose by many researchers (Kumar et al., 2014; Fan et al., 2012). Therefore, the clear presence of $1427 \mathrm{~cm}^{-1}$ and $896 \mathrm{~cm}^{-1}$ peaks in the cotton pulp and the cotton fabric revealed that they carried significant amount of cellulose.

\section{Changes of Chemical functionality during MFC extraction}

Cellulose was extracted by acid hydrolysis process that breaks down the amorphous region of the cotton waste and further reduced the size of the fibers and hence, obtained the MCC.

Figure 2 shows a greater impact of acid concentration towards chemical functionality of cellulose. When increasing the acid concentration about 50-55 \% (w/w) cellulose chemical complex began to breakdown.

\section{Morphology of MCC}

SEM image of MCC Figure 3a indicated threedimensional irregular shapes of MCC. The average size of the MCC was within 20-60 $\mu \mathrm{m}$. The rough surface of MCC (Figure 3b) clearly shows the fibrillated nature of cellulose and compact agglomeration. The width of these fibrillates was less than one micron in size. 


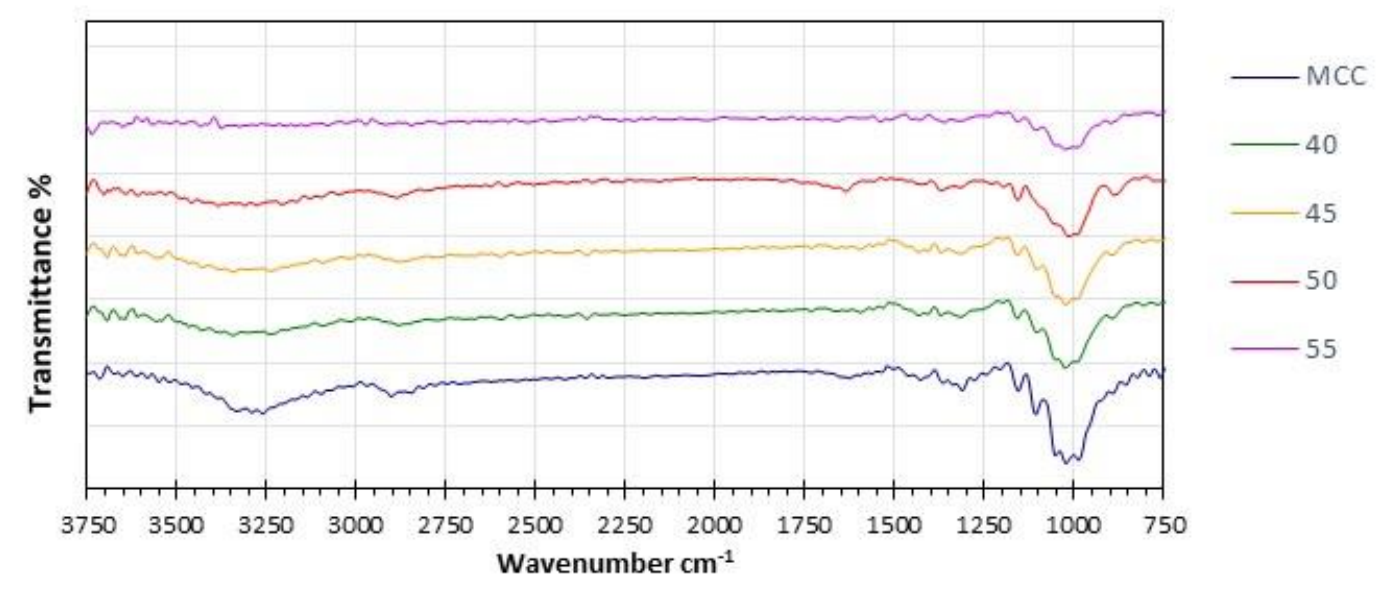

Figure 2: FTIR spectrums of MCC and acid hydrolysis samples under different $\mathrm{H}_{2} \mathrm{SO}_{4}$ concentrations
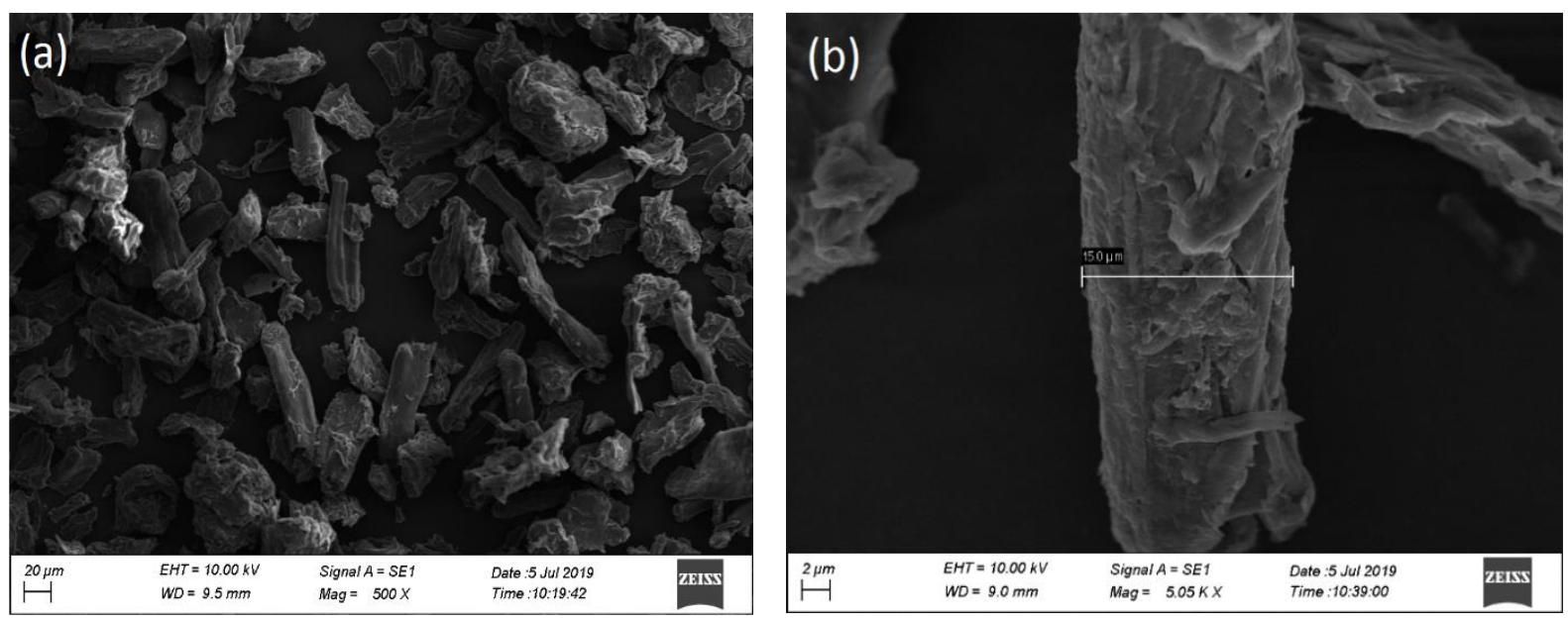

Figure 3: SEM image of (a) MCC (magnification X 500) (b) Compact fibrillated nature of MCC (magnification X 5.05K)

\section{Morphology of MFC}

Further acid hydrolysis greatly reduces the size of the cellulose by degradation and dissolution of amorphous region. The particle size greatly varies with the $\mathrm{H}_{2} \mathrm{SO}_{4}$ concentration. SEM image of MFC Figure 4a showed acid hydrolysis under $40 \%(\mathrm{w} / \mathrm{w})$ of $\mathrm{H}_{2} \mathrm{SO}_{4}$. The width of the fiber was approximately 1-3 microns and the average length was 10-20 $\mu \mathrm{m}$. Surface of the fiber was very smooth.

Figure $4 \mathrm{~b}$ shows the three-dimensional structure of cellulose fibers of the MFC hydrolysed under $45 \%(\mathrm{w} / \mathrm{w})$ of $\mathrm{H}_{2} \mathrm{SO}_{4}$. Here, the diameter and size of fibrils of hydrolysed cellulose were reduced to a great extent due to removal of all amorphous region of semicrystalline cellulose. The diameter of MFC has wide range of distribution but the size of most of the MFCs were within the range 400-600 $\mathrm{nm}$ in width and 5-15 $\mu \mathrm{m}$ in length. SEM image of MFC Figure 5c and d were acid hydrolysis samples under 50-55 \%(w/w) of $\mathrm{H}_{2} \mathrm{SO}_{4}$ concentration. The width of the cellulose fibers significantly reduced from $400-600 \mathrm{~nm}$ to $150-250 \mathrm{~nm}$ range during the acid hydrolysis. 


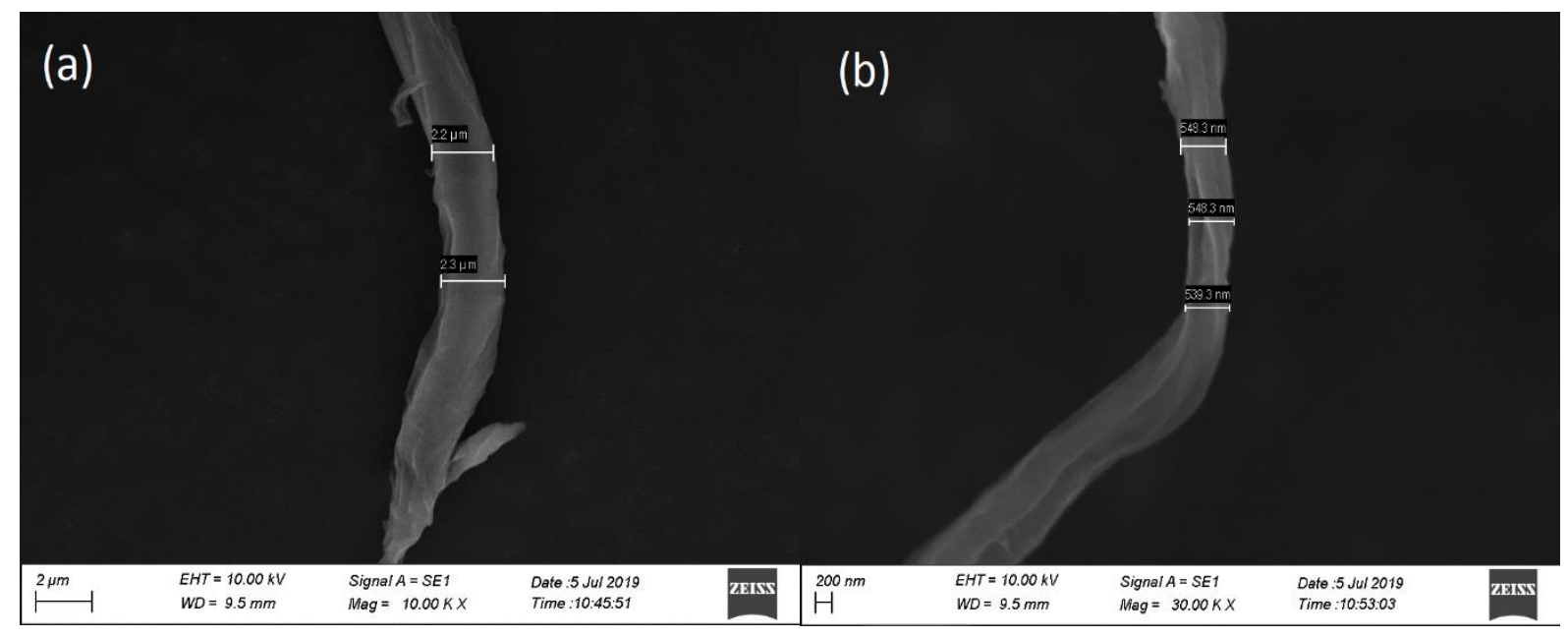

Figure 4: SEM image of (a) X1 (magnification X 10.0k) (b) X2 (magnification X $30.0 \mathrm{k}$ )

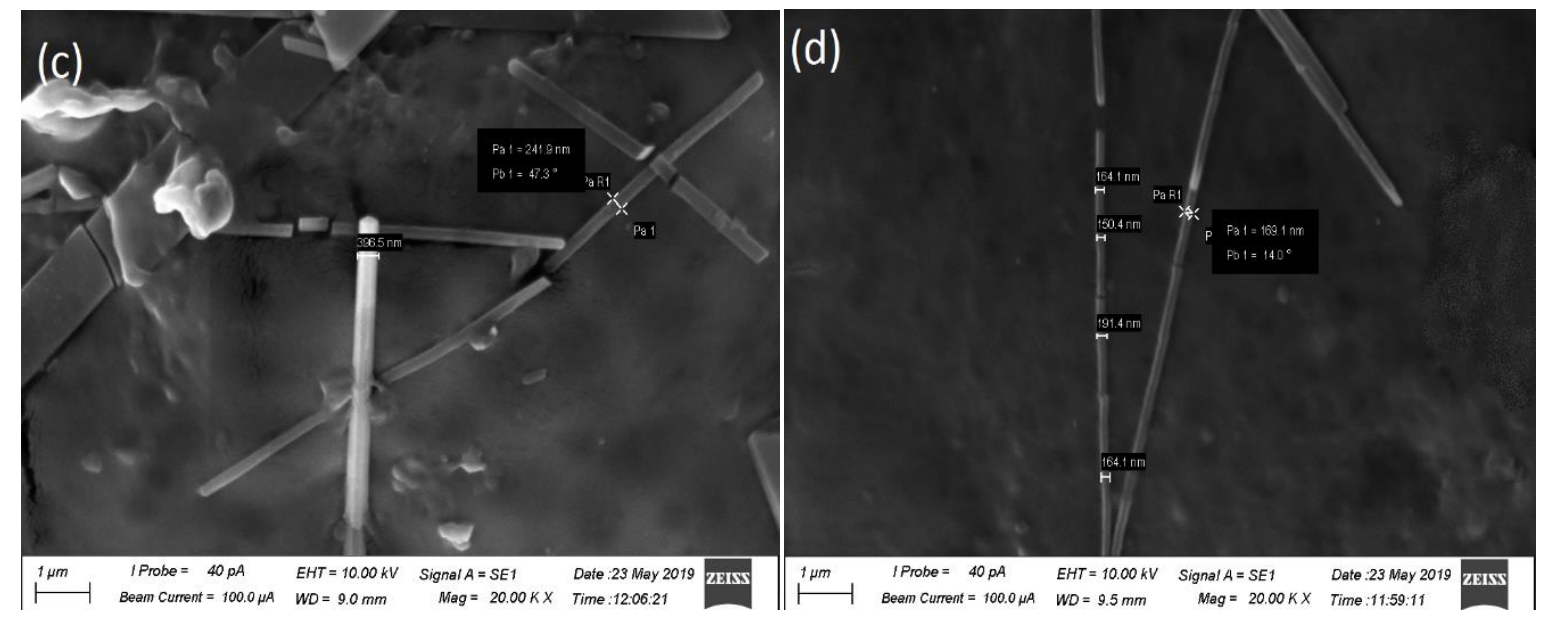

Figure 5: SEM images of (c) X3 (magnification X 20.0k) (d) X4 (magnification X 10.0k)

\section{XRD Analysis}

Cellulose I, II, III and IV polymorphy can be identified using XRD analysis. Cellulose I is considered as the native cellulose or the form found in nature. Cellulose I has two types of crystal structures; I $\alpha$ and I $\beta$. The $I \alpha$ is considered as a rare form, while I $\beta$ is common in nature. These two types were different from their packing arrangement of hydrogen bonded sheet (Poletto et al., 2013; Wu et al., 2016). The XRD diffraction pattern of bleached cotton, MCC and MFC (X2) are shown in Figure 6 . These samples observed the peaks around $2 \theta=15.1,16.3,22.6$ and 34.8 which corresponded to typical Cellulose I $\beta$ structure as reported in literature (Poletto et al., 2013).

The crystallinity index of the raw beached cotton was $36 \%$, whereas crystallinity index of MCC and MFC were $48 \%$ and $56 \%$ respectively. Raw bleached cotton contains dominant amounts of amorphous region. This amorphous region was partially removed during the acid hydrolysis steps in both MCC and MFC extraction process. The crystallinity of cellulose is known as one of the most important factors determining their mechanical and thermal properties (Tang et al., 2013). 


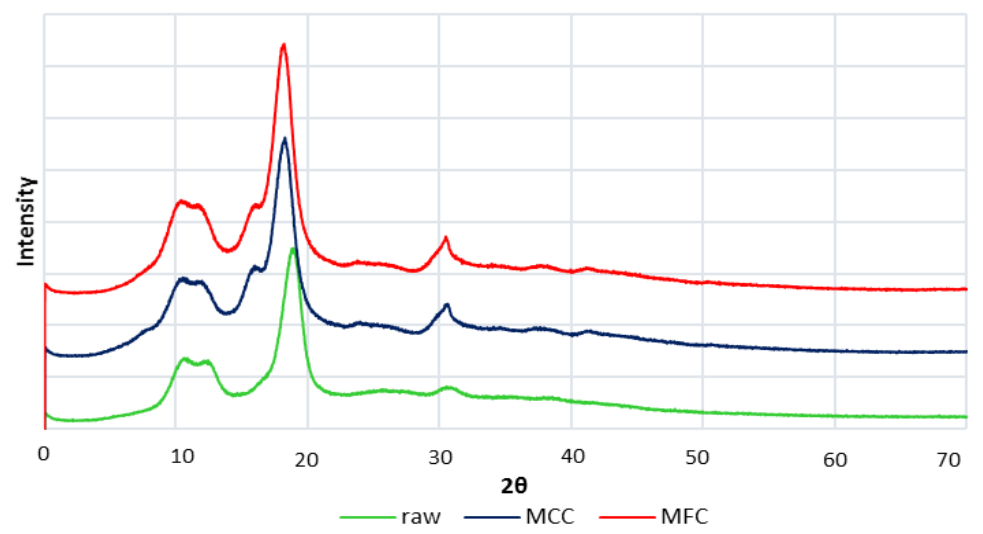

Figure 6: XRD image of raw material (Bleached cotton fabric), MCC \& MFC (X2)

\section{Thermal decomposition of cellulose}

Many studies related to the thermal decomposition of the cellulose can be found in the literature. Thermal decomposition of cellulose started at $315^{\circ} \mathrm{C}$ and persisted at 400 ${ }^{\circ} \mathrm{C}$ while maximum weight loss could be observed at $335{ }^{\circ} \mathrm{C}$. Hemicellulose usually started to decompose at $220^{\circ} \mathrm{C}$ and remaining up to $315{ }^{\circ} \mathrm{C}$ (Poletto et al., 2013). The decomposition of the bleached cotton fibers started at $275^{\circ} \mathrm{C}$, at a lower temperature than the MCC and MFC as in Figure 7. MCC and MFC started to decompose at $305-513{ }^{\circ} \mathrm{C}$.

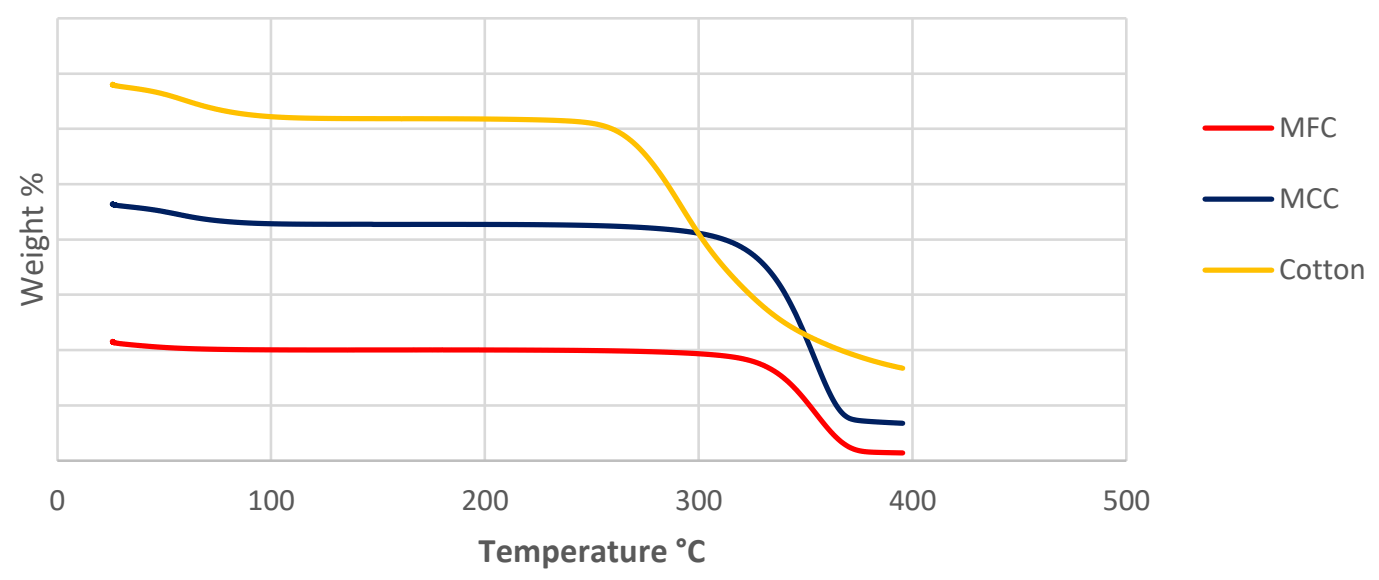

Figure 7: Thermal analysis results of bleached cotton, MCC and MFC (X2)

\section{CONCLUSIONS}

Nano scaled, value added product of MFC was successfully isolated from garment cotton waste material. Chemical purification, acid hydrolysis combined with ultrasonification processes can effectively be used to extract MFC. Concentration of the sulfuric acid highly influenced the width of the nano fibers and the yield. When the acid concentration increased, width of the nano particles reduced by dissolving its amorphous domain of cellulose and decreased the yield.
Chemical purification process of alkali and bleaching treatment gives white colour cotton fiber pulp which has properties almost similar to the fresh cotton linters. The preparation of MFC was done in two step-acid hydrolysis process. MCC was obtained as a middle product and reduced the particle size to approximately 20-60 $\mu \mathrm{m}$. MCC were again subjected to acid hydrolysis process under four different acid concentrations. SEM images clearly showed the reduction of particle size in higher acid concentrations. 
Acid concentrations above $50 \%(\mathrm{w} / \mathrm{w})$ degrade the properties of cellulose as shown in FTIR analysis. Microfibrilated cellulose with diameter ranging from $400-600 \mathrm{~nm}$ were successfully isolated with high amount of cellulose content under $45 \%(\mathrm{w} / \mathrm{w})$ acid concentration. The degree of crystallinity was increased by $20 \%$ by removing amorphous region of cellulose during acid hydrolysis and has 29\% yield by mass. Thermal analysis revealed that purified MFCs have high thermal stability compared to the native cotton. This investigation shows that the cotton fabric waste generated in garment industry can be used to isolate MFCs through acid hydrolysis process to create value added products.

\section{REFERENCES}

Bondeson, D., Mathew, A. and Oksman, K. (2006). Optimization of the isolation of nanocrystals from microcrystalline cellulose by acid hydrolysis. Cellulose 13, 171 .

Cao, J., Zhang, X., Wu, X., Wang, S. and Lu, C. (2016). Cellulose nanocrystals mediated assembly of graphene in rubber composites for chemical sensing applications. Carbohydrate polymers. 140, 8895.

Dufresne, A. (2013). Nanocellulose: a new ageless bionanomaterial. Materials Today, 16, 220-227.

Fan, M., Dai, D. and Huang, B. (2012). Fourier transform infrared spectroscopy for natural fibres. Fourier transform-materials analysis. 3, 45-68.

Hubbe, M.A., Rojas, O.R., Lucia, L.A. and Sain, M. (2008). Cellulosic Nanocomposite: A Review. BioResources. 3, 929-980.

Kahawita, K. D. H. N. and Samarasekara, A. M. P. B. (2016). Extraction and characterization of cellulosic fibers from sawmill waste. In 2016 Moratuwa Engineering Research Conference (MERCon). 343-348.
Kalia, S., Kaith, B.S. and Kaur, I. (2009). Pretreatments of natural fibers and their application as reinforcing material in polymer composites-A review. Polymer Engineering and Science. 4,1253-1272.

Khalil, H. A., Davoudpour, Y., Islam, M. N., Mustapha, A., Sudesh, K., Dungani, R. and Jawaid, M. (2014). Production and modification of nanofibrillated cellulose using various mechanical processes: a review. Carbohydrate polymers. 99, 649-665.

Kumar, A., Negi Y.S. and Choudhary, V. (2014). Characterization of Cellulose Nanocrystals Produced by Acid-Hydrolysis from Sugarcane Bagasse as Agro-Waste. Journal of Materials Physics and Chemistry. 2, 1-8.

Lee, H.V., Hamid, S.B.A. and Zain, S.K. (2014). Conversion of Lignocellulosic Biomass to Nanocellulose: Structure and Chemical Process. The Scientific World Journal. 1-20.

Poletto, M., Pistor, V. and Zattera, A. J. (2013). Structural characteristics and thermal properties of native cellulose. Cellulosefundamental aspects. 2, 45-68.

Santmarti, A. and Lee, K. (2018). Nanocellulose and sustainability production, properties, applications and case studies. Boca Raton: CRC Press.

Tang, L., Hu, Y., and Lu, Q. (2013). Preparation of cellulose nanocrystals and carboxylated cellulose nanocrystals from borer powder of bamboo. Cellulose 21, 1611-1618.

Troedec, M., Sedan, D., Peyratout, C., Bonnet, J. P., Smith, A., Guinebretiere, R. and Krausz, P. (2008). Influence of various chemical treatments on the composition and structure of hemp fibres. Composites Part A: Applied Science and Manufacturing 39, 514-522.

Wu, C. M., Lai, W. Y. and Wang, C. Y. (2016). Effects of surface modification on the mechanical properties of flax $/ \beta$ polypropylene composites. Materials. 9, 314 . 